ARTICLE

Received 22 Feb 2013 | Accepted 3 Sep 2013 | Published 4 Oct $2013 \quad$ DOl: 10.1038/ncomms3546

\title{
Structure of GrlR-GrlA complex that prevents GrlA activation of virulence genes
}

\author{
Abhilash Padavannil', Chacko Jobichen ${ }^{1}$, Erez Mills² ${ }^{2}$ Adrian Velazquez-Campoy ${ }^{3,4,5}$, Mo Li ${ }^{1}$, Ka Yin Leung ${ }^{6,7}$, \\ Yu Keung Mok', Ilan Rosenshine ${ }^{2} \&$ J. Sivaraman ${ }^{1}$
}

The locus of enterocyte effacement (LEE) is essential for virulence of enterohaemorrhagic Escherichia coli (EHEC) and enteropathogenic E. coli (EPEC). The 41 genes of the LEE encode type III secretion system proteins and three associated regulators: Ler, GrIA and GrIR. Ler is a positive regulator for most of the LEE operons, including grlRA. GrlA controls the expression of ler, ehxCABD and fIhDC operons. GrIR binds to GrIA and suppresses its function. Here we report the crystal structure of GrIR-GrlA $\Delta$ (aa 1-106) complex (2:1) and its functional characterization. We show that GrIR interacts with the Helix-Turn-Helix motif of GrlA. Moreover, GrlA binds to the promoter DNA fragments of ler, ehxCABD and fIhDC, and GrIR outcompetes with these promoter DNA sequences for the Helix-Turn-Helix motif of GrlA. These findings provide mechanistic insight into a regulatory module for the virulence of EPEC and EHEC, two important pathogens that cause devastating diseases.

\footnotetext{
${ }^{1}$ Department of Biological Sciences, National University of Singapore, 14 Science Drive 4, Singapore 117543, Singapore. ${ }^{2}$ Faculty of Medicine, Department of Microbiology and Molecular Genetics, IMRIC, The Hebrew University, Jerusalem 91120, Israel. ${ }^{3}$ Institute of Biocomputation and Physics of Complex Systems (BIFI), Joint-Unit IQFR-CSIC-BIFI, Zaragoza 50018, Spain. ${ }^{4}$ Department of Biochemistry and Molecular and Cell Biology, University of Zaragoza, Zaragoza 50009, Spain. ${ }^{5}$ Fundacion ARAID, Government of Aragon, Zaragoza 50018, Spain. ${ }^{6}$ Department of Biology, Trinity Western University, 7600 Glover Road, Langley, British Columbia, Canada V2Y 1Y1. ${ }^{7}$ State Key Laboratory of Bioreactor Engineering, East China University of Science and Technology, Shanghai 200237, China. Correspondence and requests for materials should be addressed to J.S. (email: dbsjayar@nus.edu.sg).
} 
A ttaching and effacing (AE) pathogens comprise a group of enteric pathogens, including the closely related enterohaemorrhagic Escherichia coli (EHEC) and enteropathogenic E. coli (EPEC). EPEC causes severe diarrhea in young children, whereas EHEC is a causative agent of haemorrhagic colitis and haemolytic uremic syndrome ${ }^{1,2}$. AE pathogens possess type III secretion systems (T3SS) that promote virulence. Most T3SS components and related proteins are encoded by genes in the locus of enterocyte effacement (LEE). The LEE consists of 41 genes, clustered in 5 different operons, termed LEE1-LEE5, and some additional transcription units ${ }^{3}$.

Under specific conditions, such as low temperature, the histonelike nucleoid-structuring (H-NS) protein binds to extended regions within the LEE DNA and silences the expression of the entire LEE region. This H-NS-mediated repression, however, can be countered by Ler (LEE-encoded regulator), a protein encoded by the first gene in the LEE1 operon that functions as a positive regulator of other LEE operons (LEE2-LEE5) ${ }^{4}$. Moreover, Ler is involved in both the direct and indirect regulation of additional key virulence components of EPEC and EHEC, and is thus considered as the master regulator of the virulence machineries of these pathogens. Accordingly, activation of LEE1 and ler expression is a key event in the activation of the entire virulence system of EPEC and EHEC. It is therefore not surprising that the LEE1 promoter is subjected to tight regulation by multiple factors (Fig. 1), including H-NS and Ler, which function as repressor and autorepressor, respectively. The expression of the LEE1 operon is strictly dependent on binding of the integration host factor protein immediately upstream to the $L E E 1$ promoter ${ }^{4}$, and activation of LEE1 expression is promoted by two redundant positive regulators, PerC $^{5}$ (or Pch in EHEC) and GrlA.

The grlR and grlA genes form a transcriptional unit encoding GrlR and GrlA, respectively. GrlA is a positive regulator of the LEE1 promoter and forms a positive regulatory loop with Ler. GrlR binds to GrlA and this is thought to account for the negative effect of GrlR on ler expression ${ }^{3,4,6}$. As GrlA and GrlR are co-expressed, it is expected that, in most cases, GrlA is inhibited by GrlR and that the relative levels of GrlR and GrlA are regulated. For instance, it was reported that under certain conditions GrlR is degraded by the ClpXP protease, freeing GrlA to activate Ler expression ${ }^{7}$.

Previously, we reported the structure of GrlR and elucidated its role in $L E E$ regulation ${ }^{8,9}$. GrlR forms a stable and tight dimer in solution as well as in the crystal. The dimeric architecture of GrlR is maintained by the cluster of hydrophobic interactions as well as numerous hydrogen-bonding contacts at the dimeric interface ${ }^{8}$. GrlA has also been functionally characterized ${ }^{3,4,10}$, but no structural information is available to provide insight into the regulatory mechanisms involving GrlA, GrlR and Ler.

In addition to its function as a $L E E 1$ regulator, GrlA negatively regulates the transcription of the $f h D C$ operon and thus controls flagellar gene expression. Kitagawa et al. ${ }^{11}$ demonstrated that flagellar gene expression in EHEC was strictly regulated by dual pathways: (i) post-translational control of the $\mathrm{FlhD} / \mathrm{C}$ master regulator by ClpXP-mediated protein degradation and (ii) transcriptional control of the flhDC operon through the GrlRGrlA system under LEE-inducing conditions. Moreover, deletion of $g r l R$ results in a non-motile phenotype in the EHEC O157 Sakai strain ${ }^{6}$. In many pathogens, motility is repressed by negatively regulating flhDC concomitant with T3SS induction ${ }^{11}$. GrlA-dependent repression of flagellar regulation is important for efficient adhesion of EHEC to host cells ${ }^{6,11}$ and perhaps also to avoid detection by the host innate immune sensors TLR5 and NLRP4 (refs 12,13). GrlA is also implicated in the transcriptional activation of the ehxCABD operon in EHEC ${ }^{14,15}$. The ehxA gene encodes haemolysin, and $e h x C$ acts as a modifying factor that

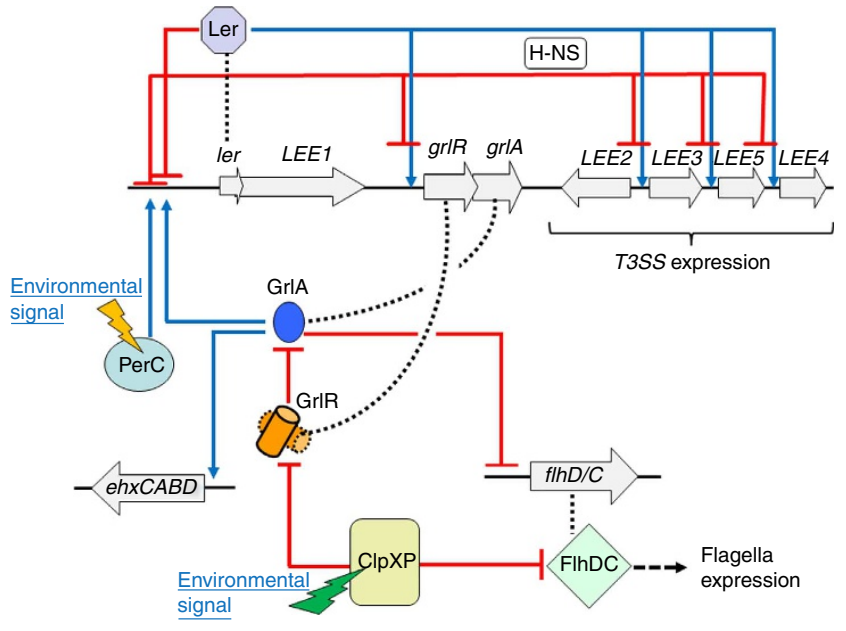

Figure 1 | Schematic of the regulatory circuits related to the GrIR-GrIA complex. We propose the following model based on results presented in this report as well as results previously published by others and by us. The grlR and grlA genes form a bicistronic operon located within the LEE. Under non-inducing conditions, the expression of the entire $L E E$, including $g r \mid R A$, is suppressed by a H-NS protein, and the activity of the residual GrlA is suppressed by GrIR via direct interaction (repression is indicated by red lines). The expression of the entire system can be activated by two alternative modes. The first involves specific environmental cues that turn on PerC expression; this, in turn, activates the expression of ler (activation is indicated by blue lines). Ler then antagonizes H-NS and stimulates the expression of all of the other LEE operon components, including grIRA. The produced GrlA directly activates ler expression to establish the GrlA-Lerpositive feedback loop. Consequently, GrlA indirectly promotes the expression of all LEE genes, directly activates the expression of the ehx operon, and represses the expression of the flagella master regulator flhDC. The GrlA-Ler loop is restrained by the autorepressive action of Ler as well as by GrIR, which directly binds to GrIA to inhibit its interaction with target DNA. The second mode of activation involves environmental signals that trigger the ClpXP protease to degrade GrIR, thus releasing GrlA to activate ler expression and mediate the establishment of the Ler-GrIA-positive loop described above.

converts inactive haemolysin into its active form by the addition of a fatty acid group ${ }^{16}$; the specific secretion machinery for EhxA is encoded by ehxB and $e h x D^{17}$.

The in vitro instability of GrlA has previously hindered structural studies and other attempts to elucidate the regulatory mechanism involving Ler, GrlA and GrlR. Here we report the crystal structure of GrlA $\Delta$ (aa1-106) in complex with GrlR, refined up to $2.7 \AA$ resolution, and the associated functional studies. The structure is asymmetric with a stoichiometry of 2 GrlR:1GrlA $\Delta$. In addition, we identify a novel regulatory mechanism by which GrlR interacts with GrlA at its Helix-Turn-Helix (HTH) motif, preventing GrlA from binding to its target promoter DNA.

\section{Results}

Overall structure of the GrlR-GrlA $\Delta$ complex. We initially attempted to determine the structure of full-length GrlA in complex with GrlR. However, the full-length GrlR-GrlA complex did not yield diffraction quality crystals, presumably because of the unstable nature of GrlA. As a result, we generated GrlR-GrlA complexes with varying lengths of GrlA. A complex of GrlR with GrlA $\Delta$ (aal-106) (Fig. 2a) yielded diffraction quality crystals. The structure was determined and refined up to $2.7 \AA$ resolution 


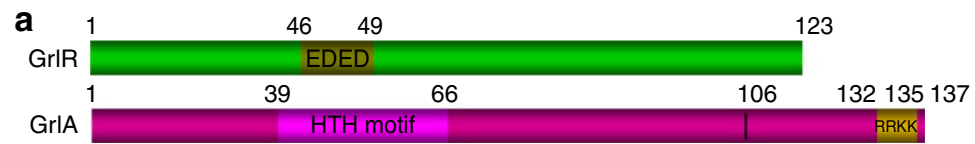

b

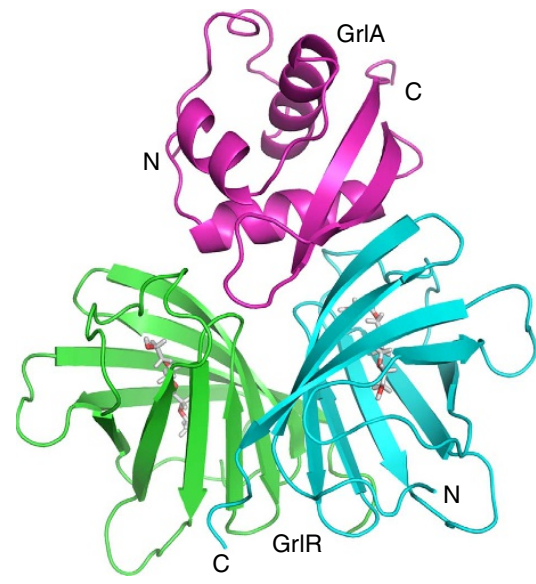

C

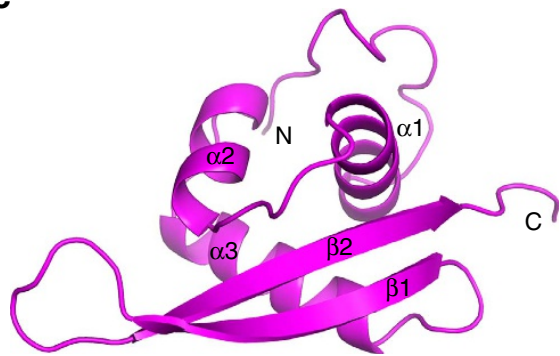

d
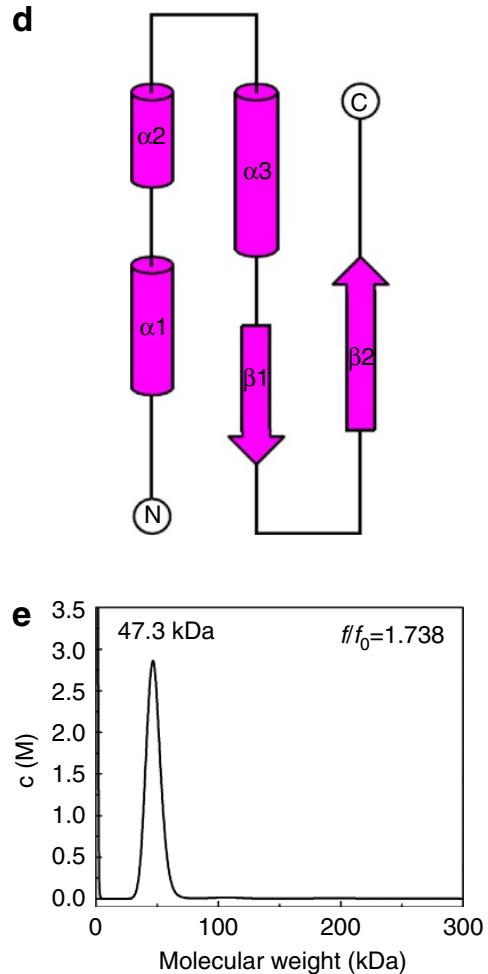

Figure 2 | Structure of the GrIR-GrIA $\Delta$ heterotrimeric complex. (a) GrlR and GrlA proteins with motifs. (b) Crystal structure of the GrlR-GrlA $\Delta$ complex. The two monomers of GrlR are shown in green (monomer A) and cyan (monomer B). GrlA $\Delta$ is shown in magenta. The ligand Triton X-100 is shown as sticks. (c) Structure of GrlA $\Delta$. (d) The topology diagram of the GrlA $\Delta$ molecule. Structure-related figures are prepared using PyMol ${ }^{35}$. (e) The stoichiometric ratio of WT GrIR-GrlA complex protein was investigated in an analytical ultracentrifuge by monitoring their sedimentation properties in a sedimentation velocity experiment. The peak corresponds to a molecular weight of $47.3 \mathrm{kDa}$, indicating the presence of two molecules of $6 \mathrm{His}-\mathrm{GrIR}$ and one molecule of GrlA in the complex.

(Table 1 and Fig. 2b). The first 8 residues and last 11 residues of GrlA $\Delta$ were not well-defined in the electron density map and were not included in the model. GrlR is a $\beta$-barrel protein, structurally similar to our previously determined GrlR structures (root mean squared deviation (r.m.s.d.) of $0.87 \AA$ for all $\mathrm{C}_{\alpha}$ atoms) $)^{8,9}$, whereas GrlA $\Delta$ mainly comprises a HTH motif (aa 39-66) and an anti-parallel $\beta$-sheet in the carboxy terminus (Fig. 2c,d). The complex consists of one dimer of GrlR bound to a monomer of GrlA $\Delta$ (2:1 stoichiometric ratio), with 15 hydrogenbonding contacts $(<3.2 \AA)$ formed between GrlR and GrlA $\Delta$, and a buried area of 1,043.8 $\AA$ (ref. 2). This GrlR:GrlA stoichiometric ratio was further verified by analytical ultracentrifugation, which showed that the complex is of $47.3 \mathrm{kDa}$, corresponding to two molecules of 6His-GrlR and one molecule of GrlA (Fig. 2e). This is consistent with the gel filtration experiment (Supplementary Fig. S1a,b).

Sequence and structural homology of GrlA. GrlA homologues are present in over 100 species of bacteria, including EPEC, EHEC, Citrobacter rodentium, Shigella sp. and Salmonella sp. with no structures available to date. GrlA shares 33\% sequence identity ( $46 \%$ similarity) with CaiF, a potential transcriptional activator of carnitine metabolism in E. coli, and belongs to the PFAM family of DUF1401 (http://pfam.sanger.ac.uk/family/ DUF1401). Despite a very low sequence identity $(<7 \%)$, the
DALI ${ }^{18}$ search for structural homologues of GrlA identified several regulatory proteins. The closest homologues are also HTH motif-containing proteins, such as a transcriptional regulator from Methanosarcina mazei (PDB 3R0A; r.m.s.d. $2.8 \AA$ for $72 \mathrm{C}_{\alpha}$ atoms), a DNA-binding protein from Pyrococcus horikoshii OT3 (PDB 1ULY; r.m.s.d. $2.5 \AA$ for $67 \mathrm{C}_{\alpha}$ atoms) and a doublestranded RNA-specific adenosine deaminase (PDB 3F23; r.m.s.d. $2.6 \AA$ for $61 \mathrm{C}_{\alpha}$ atoms). These structural similarities suggest that these homologues may have similar functions, such as in transcriptional regulation.

GrlR interacts with the HTH and C-terminal regions of GrlA. The crystal structure of the complex revealed that GrlR interacts with the HTH motif region of GrlAs (Fig. 3a,b and Supplementary Fig. S2a,b). The residues R53, R54, R64, R65 and K66 from the HTH region of GrlA $\Delta$ are involved in hydrogenbonding contacts with GrlR. Our previous studies with GrlA ${ }^{8}$ suggested that the C-terminal region of GrlA might be involved in binding to GrlR (please refer to the Discussion section). Therefore, we sought to independently verify the contribution of the amino-terminal HTH motif and the C terminus of GrlA in its interaction with GrlR. To verify this, we created three constructs by substituting the abovementioned five interacting amino acids of the HTH motif region with alanine (denoted as GrlA5M), truncating the C-terminal region of GrlA 
$(\mathrm{GrlA} \Delta)$, or both mutations (GrlA $\Delta 5 \mathrm{M})$. Thus, the various GrlA constructs used in these interaction studies include MBP-GrlA, MBP-GrlA5M, MBP-GrlA $\Delta$ and MBP-GrlA $\Delta 5 \mathrm{M}$. The circular dichroism spectrum of the wild type (WT) and mutants of GrlA suggest that the mutants have the same fold as the WT GrlA (Supplementary Fig. S3).

The $K_{\mathrm{d}}$ for the interaction between GrlR and MBP-GrlA was determined by isothermal titration calorimetry (ITC). GrlR interacts with MBP-GrlA with an $\sim 35$-fold higher affinity

\begin{tabular}{|c|c|}
\hline & SelMet SAD \\
\hline \multicolumn{2}{|l|}{ Data collection } \\
\hline Space group & $\mathrm{C} 222_{1}$ \\
\hline \multicolumn{2}{|l|}{ Cell dimensions } \\
\hline$a, b, c(\AA)$ & $a=83.19, b=121.21, c=84.83$ \\
\hline$\alpha, \beta, \gamma\left({ }^{\circ}\right)$ & 90 \\
\hline Wavelength & 0.97893 \\
\hline Resolution $(\AA)$ & $50.0-2.62(2.67-2.62)$ \\
\hline${ }^{\mathrm{a}} R_{\mathrm{sym}}$ or $R_{\text {merge }}$ & $0.12(0.39)$ \\
\hline$|/ \sigma|$ & $16.23(3.56)$ \\
\hline Completeness (\%) & $98.0(82.8)$ \\
\hline Redundancy & $13.9(10.6)$ \\
\hline \multicolumn{2}{|l|}{ Refinement } \\
\hline Resolution $(\AA)$ & $15.0-2.7$ \\
\hline No. of reflections & 22,108 \\
\hline${ }^{\mathrm{b}} R_{\text {work }} /{ }^{\mathrm{C}} R_{\text {free }}$ & $0.18 / 0.23$ \\
\hline \multicolumn{2}{|l|}{ No. of atoms } \\
\hline Protein & 2,543 \\
\hline Ligand/ion & 26 \\
\hline Water & 15 \\
\hline \multicolumn{2}{|l|}{$B$-factors } \\
\hline Protein & 53.9 \\
\hline Ligand/ion & 54.80 \\
\hline Water & 45.7 \\
\hline \multicolumn{2}{|l|}{ r.m.s.d. } \\
\hline Bond lengths $(\AA)$ & 0.01 \\
\hline Bond angles $\left({ }^{\circ}\right)$ & 1.283 \\
\hline
\end{tabular}

r.m.s.d., root mean squared deviation; SAD, single-wavelength anomalous dispersion.

${ }^{a} R_{\text {sym }}=\Sigma||_{\mathrm{i}}-\left.\langle I\rangle|/ \Sigma|\right|_{\mathrm{i}} \mid$ where $l_{\mathrm{i}}$ is the intensity of the ith measurement, and $\langle l\rangle$ is the mean intensity for that reflection.

${ }^{b} R_{\text {work }}=\Sigma\left|F_{\text {obs }}-F_{\text {calc }}\right| / \Sigma\left|F_{\text {obs }}\right|$ where $F_{\text {calc }}$ and $F_{\text {obs }}$ are the calculated and observed structure factor amplitudes, respectively.

${ }^{C} R_{\text {free }}=$ as for $R_{\text {work, }}$ but for $10.0 \%$ of the total reflections chosen at random and omitted from refinement. Individual B-factor refinement was carried out.

${ }^{*}$ Values in the parenthesis are the highest resolution bin values.
$\left(K_{\mathrm{d}}=0.031 \mu \mathrm{M}\right)$ than with MBP-GrlA $\Delta\left(K_{\mathrm{d}}=1.1 \mu \mathrm{M}\right)$ (Fig. $4 \mathrm{a}$ and Supplementary Table S1). Similarly, the $K_{\mathrm{d}}$ for the interaction between GrlR and MBP-GrlA5M was also higher $\left(K_{\mathrm{d}}=0.96 \mu \mathrm{M}\right)$ than the WT interaction (Fig. $4 \mathrm{~b}$ and Supplementary Table S1). Besides the 35- and 31-fold reductions in affinity, respectively, MBP-GrlAD and MBP-GrlA5M also showed thermodynamic profiles distinct from the WT MBP-GrlA. Although the MBP-GrlA interaction with GrlR is enthalpically and entropically favourable $\left(\Delta H=-4.8 \mathrm{kcal} \mathrm{mol}^{-1}\right.$ and $\left.-T \Delta S=-5.4 \mathrm{kcal} \mathrm{mol}^{-1}\right)$, the other two protein variants (GrlA $\Delta$ and GrlA5M) showed an enthalpically driven interaction, with unfavourable entropic contributions $\left(\Delta H=-21.0 \mathrm{kcal} \mathrm{mol}^{-1}\right.$ and $-T \Delta S=12.9 \mathrm{kcal} \mathrm{mol}^{-1}$, for MBP-GrlA $\Delta ; \quad \Delta H=-9.6 \mathrm{kcal} \mathrm{mol}^{-1}$ and $\mathrm{T} \Delta \mathrm{S}=$ $1.3 \mathrm{kcal} \mathrm{mol}^{-1}$, for GrlA5M; Supplementary Table S1).

GrlR interacted with the WT MBP-GrlA or MBP-GrlA $\Delta$ with a stoichiometric ratio of 2:1. However, the stoichiometric ratio between GrlR and MBP-GrlA5M was 1:1, which suggests that two MBP-GrlA5M molecules bind with a dimeric GrlR (Supplementary Table S1). The MBP-GrlA $\Delta 5 \mathrm{M}$ construct did not show binding to GrlR.

Subsequently, we examined the role of each of the aforementioned key residues in mediating the interaction between GrlR and GrlA by pull-down assay. MBP-GrlA $\Delta$ containing double amino acid substitutions (MBP-GrlAA (R53A R54A), MBP-GrlA $\Delta$ (R64A R65A) and MBP-GrlAA (R65A K66A)) did not interact with GrlR (Fig. 5a and Supplementary Figs S4a,b and S5a), whereas single alanine substitutions had little effect on the GrlA $\Delta$ GrlR interaction (Supplementary Fig. S5b). Consistent with the ITC results, MBP-GrlA, MBP-GrlA $\triangle$ and MBP-GrlA5M pulled down GrlR, whereas MBP-GrlA $\Delta 5 \mathrm{M}$ did not (Supplementary Fig. $\mathrm{S} 5 \mathrm{c}$ ). We further verified the role of the key residues of GrlR in mediating GrlA binding, which shows that alanine substitution at D35 and E60 of GrlR could abolish its binding to MBP-GrlA $\Delta$ (Fig. 5b and Supplementary Fig. S5d). Moreover, these results were confirmed using a pETDuet-1-grlR-grlA $\Delta$ co-expression and co-purification system with $6 \mathrm{His}$ tag on GrlR and a tagless GrlA $\Delta$ (Supplementary Figs S6a,b, S7 and S8). Taken together, these results show that GrlR-GrlA interaction involves both the HTH motif region and the $\mathrm{C}$-terminal region of GrlA.

ler Promoter region and GrlR compete for HTH motif of GrlA. Previous studies demonstrated that GrlA binds to DNA via its HTH motif ${ }^{10}$, and the crystal structure of the GrlR-GrlA $\Delta$ complex revealed that GrlR interacts with the $\mathrm{HTH}$ motif region of GrlA $\Delta$ (Fig. 3a,b and Supplementary Fig. S2a,b). On the basis

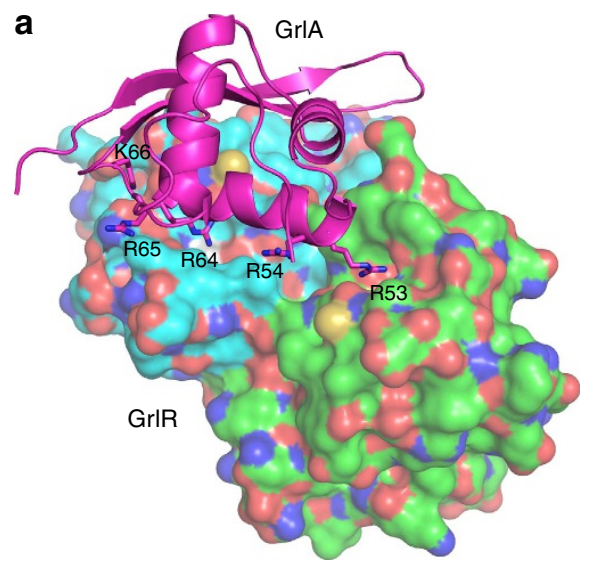

b

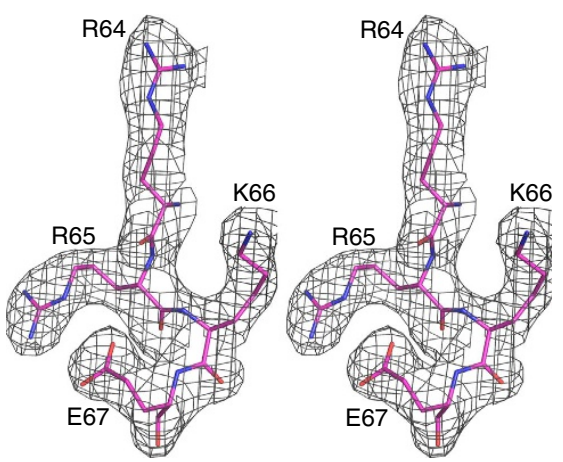

Figure 3 | Structure of the GrIR-GrIA $\Delta$ interacting surface. (a) The GrlR dimer is shown in surface representation and GrlA $\Delta$ is shown as a cartoon. The interacting residues of GrlA $\Delta$ are shown as sticks. (b) Final $2 F o-F c$ electron density map (contoured at $1 \sigma$ ) for the key residues of GrlA $\Delta$. 

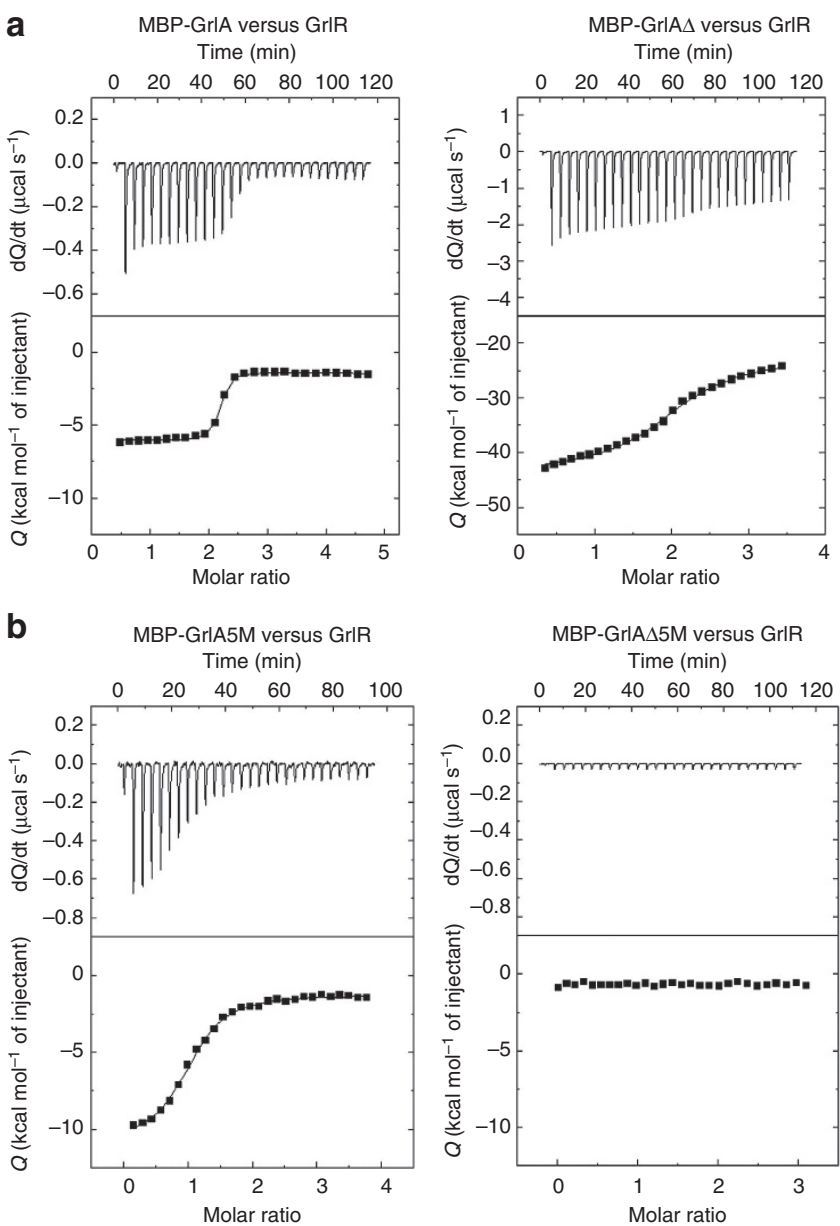

Figure 4 | Role of the C-terminal region and the HTH motif region of GrIA in GrIR-GrlA interactions. (a) The binding affinities of MBP-GrIA/ MBP-GrIA $\Delta$ to GrIR were determined using ITC. Representative ITC profiles are shown. The GrlA proteins used are indicated above each panel. The upper part of each panel shows the thermogram (thermal power versus time) after baseline correction and the bottom part of each panel shows the binding isotherm (normalized heat versus molar ratio of reactants) for each injection. The solid lines in the bottom part of each panel show the fit of the data to a function based on a single class of binding site model. (b) The binding affinities of GrIR to MBP-GrIA/MBP-GrlA $\Delta$ with substitutions in the $\mathrm{HTH}$ motif region ( $5 \mathrm{M}$ ) were determined using ITC ( $5 \mathrm{M}$ refers to substitutions at R53A, R54A, R64A, R65A and K66A). The binding constants $\left(K_{\mathrm{a}}\right.$ and $\left.K_{\mathrm{d}}\right)$, number of binding sites $(N)$, enthalpy $(\Delta H)$ and entropy $(\Delta S)$ are provided in Supplementary Table S1.

of these observations, we proposed that promoter DNA and GrlR would compete for the HTH motif region of GrlA. To test this prediction, we adopted a structure-guided alanine substitution analysis created in the HTH motif region of full-length MBPGrlA at the following positions: R53, R54, R64, R65 and K66 of the HTH motif and Y78. Electrophoretic mobility shift assays (EMSAs) were performed to study the interaction of the GrlA mutants with a DNA fragment containing the ler promoter and regulatory regions (Fig. 6a,b). Mutants with single alanine substitutions at R53, R54, R65 and K66 exhibited mobility shifts that were less than that observed for the WT GrlA, indicating a reduced affinity for DNA. The MBP-GrlA R64A mutant and a double mutant of MBP-GrlA (R65A K66A) failed to interact with DNA (Fig. 6b, lanes 4 and 8). Furthermore, the Y78A mutant formed a shifted complex that was comparable to the WT GrlA-DNA complex (Fig. 6b, lane 7).
To determine whether the addition of GrlR could dissociate MBP-GrlA from the ler promoter, a competitive EMSA assay was carried out (Fig. 6c). Under the given experimental conditions, when the concentration of GrlR was increased to $0.3 \mu \mathrm{M}$, the MBP-GrlA-DNA complex dissociated. No mobility shift of the DNA was detected at higher GrlR concentrations $(>0.3 \mu \mathrm{M})$. To verify the formation of the GrlR-GrlA complex, a preformed MBP-GrlA-DNA complex bound to amylose beads was titrated against GrlR and washed with DNA-binding buffer. Beads from each of these stages and washes were simultaneously analysed using SDS-polyacrylamide gel electrophoresis (SDS-PAGE) and EMSA assay. The EMSA gel analysis showed no apparent shift in the DNA as compared with DNA alone after the MBP-GrlADNA complex was titrated with GrlR (Supplementary Fig. S9a, lane 6). SDS-PAGE analysis showed bands corresponding to MBP-GrlA and GrlR in the final beads (Supplementary Fig. S9b, lane 9). These results indicate that DNA bound to MBP-GrlA was replaced by GrlR. Besides, these findings show that GrlR outcompetes with DNA to bind to the GrlA HTH motif.

Next, we sought to verify the ability of DNA to pull out GrlA from the GrlR-GrlA complex. A preformed GrlA-GrlR complex was incubated with increasing concentrations of DNA $\left(P_{l e r}\right)$ for about $30 \mathrm{~min}$ and then analysed using EMSA assay. There was no apparent shift in the DNA incubated with preformed GrlA-GrlR complex compared with the control DNA fragment (Supplementary Fig. S10). These results clearly show the inability of DNA to displace GrlR from the GrlR-GrlA complex.

The GrlR-GrlAs complex is functional in vivo. We next determined whether the GrlA $\Delta$ could form a functional regulatory complex with DNA in vivo. To this end, we employed the EPEC-null strain $(\triangle g r l R A:: k n)$, which contains a ler-gfp transcriptional fusion (GY2155), and for which the green fluorescent protein (GFP) expression levels report the activity of the ler promoter. This strain was transformed with a plasmid expressing GrlA or GrlA $\Delta$, and the GFP levels were compared by western blot analysis using an antibody directed against GFP. The results show that the activity of the ler promoter in the strain expressing the full-length GrlA and GrlA $\Delta$ is almost the same, indicating that GrlA $\Delta$ is functional in vivo (Fig.7a and Supplementary Fig. S11a). This finding also suggests a negligible role of the last 31 amino acids of GrlA in terms of ler promoter binding. The strain expressing both GrlR and GrlA showed less activity as compared with the strain expressing GrlA alone, illustrating the repressive activity of GrlR. Repression by GrlR in the GrlA $\Delta$-expressing strain was comparable with that expressing both GrlR and full-length GrlA (Fig.7a and Supplementary Fig. S11a).

An additional readout for the functionality of GrlA $\Delta$ is the secretion of EspB, which reflects ler expression and functionality ${ }^{19}$. EspB is a major T3SS effector protein and EspB secretion acts as an indicator for the formation of a functional $\mathrm{T} \mathrm{SS}^{20}$. Our measurements of EspB secretion is in agreement with the data obtained with the ler-gfp promoter assay. The secretion assay showed comparable EspB secretion between $\Delta g r l R A:: k n$-null strains supplemented with a plasmid expressing either GrlA $\Delta$ or full-length GrlA (Fig. 7b and Supplementary Fig. S11b). Similarly, a comparable amount of EspB was secreted from the mutant expressing GrlRA or GrlRA $\Delta$. Although deletion of the C-terminal region of GrlA resulted in a substantial decrease in the affinity between GrlA and GrlR (Fig. 4a), we did not observe significant phenotypic consequences under the experimental conditions used in this study (Fig. 7a,b and Supplementary Fig. S11a,b). This suggests that as long as the $\mathrm{N}$-terminal region of GrlA is intact, the protein remains functional. The role of the 

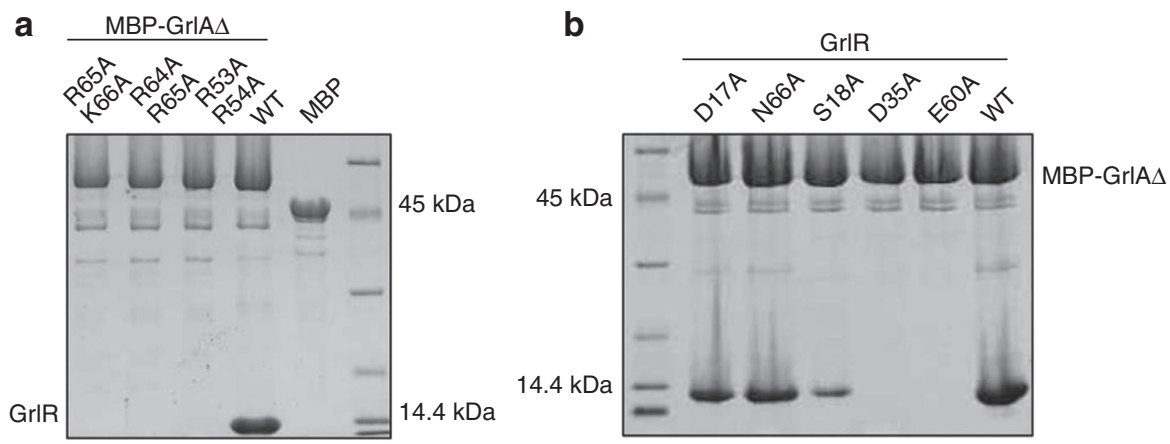

Figure 5 | Role of the key residues in the HTH motif region in GrIR-GrIA $\Delta$ interactions. (a) Pull-down assay to show the binding of GrlA $\Delta$ or mutant variants with GrIR. MBP-GrIA $\Delta$ proteins were bound to amylose beads, incubated with $6 \mathrm{His}-\mathrm{GrIR}$ overnight and washed. The eluted proteins were separated by $12.5 \%$ SDS-PAGE and the gels stained with Coomassie brilliant blue. The GrlA derivatives employed are indicated above the lanes: MBPGrlA $\Delta$ (R65A K66A), MBP-GrlA $\Delta$ (R64A R65A), MBP-GrlA $\Delta$ (R53A R54A), WT MBP-GrlA $\Delta$ and MBP. (b) Pull-down assay to show the binding of GrlA $\Delta$ with GrlR or the GrlR mutants. The GrIR mutants employed are indicated above the lanes: GrIR D17A, GrIR N66A, GrIR S18A, GrIR D35A GrIR E60A and WT GrIR. The input washes and final elution of the representative mutants are shown in Supplementary Fig. S4a. The additional bands seen on the SDS-PAGE (a) were identified as MBP using peptide mass fingerprint analysis (Supplementary Fig. S4b). Western blot analysis of the pull-down assay (a,b) was carried out using anti-MBP and anti-His antibodies (Supplementary Fig. S5a,d). The pull-down results were confirmed in a co-expression, co-purification pETDuet-gr/R-grlA $\Delta$ system and analysed on a $12.5 \%$ native gel (Supplementary Figs S6a,b, S7 and S8).

additional interaction from the C-terminal region of GrlA thus remains to be identified.

The key HTH residues are required for GrlA function in vivo. EspB secretion was further used to examine the role of the key HTH residues in the regulatory functions of GrlA. To eliminate the negative regulatory effect of GrlR, we transformed the $\Delta g r l R A:: k n$-null strain with a plasmid expressing GrlA $\Delta$. Bacteria were grown under conditions that favoured positive regulation of the T3SS by $\mathrm{GrlA}^{5}$, and the amount of EspB secretion was determined by western blot analysis (Fig. 8a and Supplementary Fig. S11c). Secretion of EspB was elevated when the $\Delta g r l R A:: k n-$ null strain was supplemented with $\operatorname{GrlA} \Delta$, and GrlA with alanine substitutions at R65 or K66 induced efficient EspB secretion (Fig. 8a and Supplementary Fig. S11c). In contrast, the GrlA $\Delta$ R64A mutant failed to induce EspB secretion (Fig. 8a and Supplementary Fig. S11c) as did the GrlAs (R65A K66A) double mutant. Taken together, the results show that substitutions in key residues in the GrlA HTH region, which hamper binding to the ler regulatory region, elicit a profound effect on the ability of the bacteria to assemble a functional T3SS and thus on the bacterial virulence. These effects are presumably related to reduced activity of the ler promoter and consequently reduced expression of some or all of the LEE operons.

To more directly test the role of HTH key residues in the activation of the ler promoter, we employed the ler-gfp promoter assay described above (Fig. $8 \mathrm{~b}$ and Supplementary Fig. S11d). The EPEC-null strain $(\Delta g r l R A:: k n)$, which contains a ler-gfp transcriptional fusion (GY2155), was transformed with a plasmid expressing various grlA mutants. Substitutions such as R65A and K66A were well tolerated, unlike R54A and R64A, where the activity of the ler promoter was reduced substantially. The results from both the secretion assay and the ler-gfp promoter assays were thus consistent, validating the importance of the key residues in the $\mathrm{HTH}$ motif in mediating the function of GrlA as a positive regulator of ler and subsequently as positive regulator of the T3SS biogenesis.

GrlR competes with $f h D C$ and $e h x C A B D$ operons for GrlA binding. We next examined whether the competition between the ler promoter region and GrlR for binding to GrlA was unique to the ler regulatory region or a more general mode of operation of the GrlR-GrlA system. To this end, we examined two additional GrlA targets: the flhDC and ehxCABD promoter regions ${ }^{11,14,15}$. We performed EMSA assays by incubating MBP-GrlA with a DNA fragment containing the $f h D C$ promoter region. The addition of GrlA shifted the DNA, indicating that MBP-GrlA had bound to the promoter region of the flhDC operon (Supplementary Fig. S12a). The HTH mutants that were previously shown to alter GrlA binding to the ler regulatory region showed a similar pattern of binding to the flhDC regulatory region (Supplementary Fig. S12b). A competitive EMSA assay also indicated that the addition of GrlR clearly reduced the interaction of GrlA with the $f l h D C$ regulatory region, presumably by binding to GrlA and displacing the DNA (Supplementary Fig. S13).

With respect to the ehxCABD operon, EMSA assays showed that MBP-GrlA specifically binds to the ehx promoter region. Subsequent EMSA experiments using mutant MBP-GrlA showed various amounts of reduction in the mobility shifts, consistent with those seen for GrlA binding to ler and flhDC promoter regions (Supplementary Figs S14a-c and S15). Cumulatively, our findings suggest that the general mode of operation of the GrlRGrlA system involves mutually exclusive binding of the GrlA $\mathrm{HTH}$ motif with either GrlR or its target DNA.

\section{Discussion}

Extensive functional analyses have shown that the GrlR-GrlA is a key regulatory complex involved in the direct or indirect regulation of most virulence genes in $\mathrm{AE}$ pathogens, including EPEC, EHEC and C. rodentium ${ }^{3,4,6,8}$. These studies include demonstration of the regulatory role of the GrlR-GrlA system in three independent operons: LEE1, flhDC and ehxCABD ${ }^{4,11,21}$. GrlA positively regulates the expression of ler, the first gene in the LEE1 operon, which in turn regulates the expression of various downstream genes involved in T3SS biogenesis ${ }^{4}$. In addition to $L E E 1$, GrlA is also involved in the positive regulation of ehx operons and the negative regulation of the $f h D C$ operon (Fig. 1). GrlR binds directly to GrlA and functions as an anti-regulator ${ }^{4}$. However, the molecular details of the regulation of the GrlRGrlA complex have, until now, remained elusive because of the lack of structural details. Here we close this gap, reporting the 
a

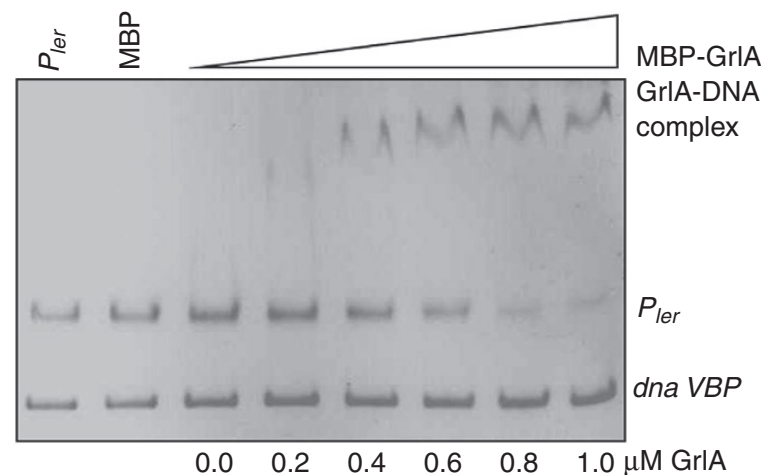

b

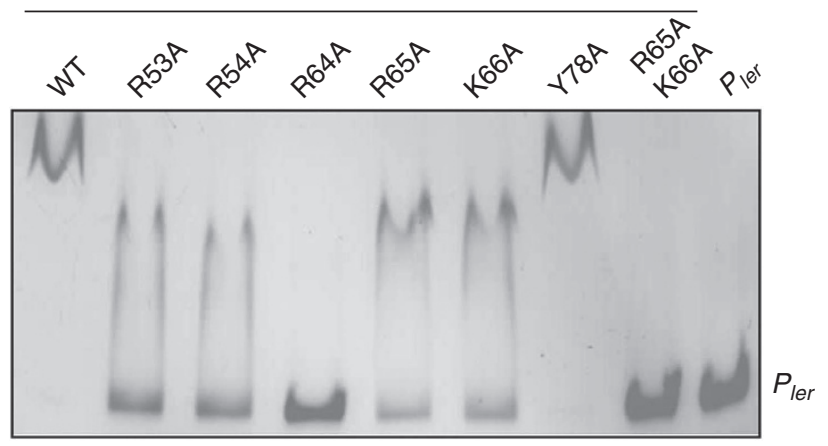

C

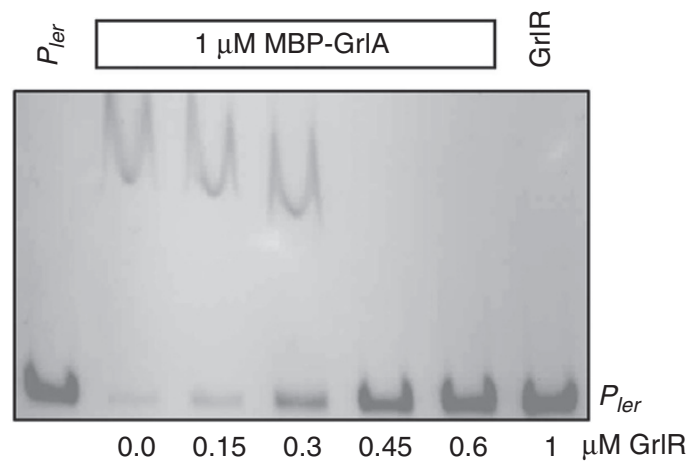

Figure 6 | Interaction of GrIA with the ler regulatory region in vitro.

(a) EMSA assay for PCR DNA fragments comprising the ler regulatory region (ler - 275/ + 217; numbers indicate the number of base pairs upstream and downstream from the functional ATG start codon, respectively) DNA VBP is a non-specific DNA. (b) EMSA assay with substituted MBP-GrlA proteins. PCR DNA fragments comprising the regulatory region (ler $-275 /+217)$ were mixed and incubated with $1.0 \mu \mathrm{M}$ of purified MBP-GrlA, or with different substituted mutants. Free DNA and protein-DNA complexes were resolved by 5\% PAGE and stained with ethidium bromide. The GrlA species used include: WT GrlA, GrlA R53A, GrlA R54A, GrlA R64A, GrlA R65A, GrlA K66A, GrlA Y78A,

GrIAR65AK66A and ler pr (ler - 275/217). (c) Competitive EMSA assay aimed at testing competition between DNA and 6His-GrlR for binding to MBP-GrIA. PCR DNA fragments comprising the regulatory region $($ ler $-275 /+217)$ were mixed and incubated with $1 \mu \mathrm{M}$ purified MBP-GrlA for $15 \mathrm{~min}$, then combined with increasing concentrations $(0.0,0.15,0.3$, 0.45 and $0.6 \mu \mathrm{M}$ ) of $6 \mathrm{His}-\mathrm{GrIR}$ for an additional $15 \mathrm{~min}$. The complexes and free DNA were separated on a $5 \%$ native polyacrylamide gel and stained with ethidium bromide (ler pr: ler $-275 /+217$ ).

crystal structure of the GrlR-GrlAs complex, along with supportive functional studies.

In a previous study, we reported the binding between GrlR and GrlA mediated by the possible interaction of an ${ }^{46} \mathrm{EDED}^{49}$ motif
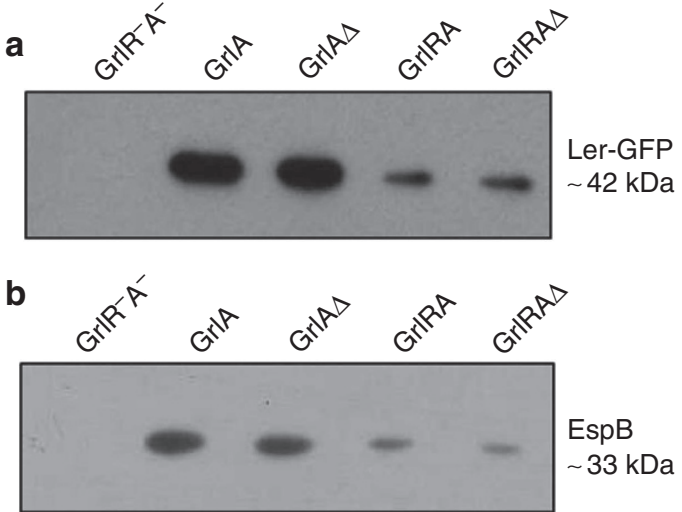

Figure 7 | In vivo functionality of GrIR-GrIA $\Delta$ asymmetric complex.

(a) Immunoblot analysis using anti-GFP antibodies to compare the expression of GFP via the ler promoter. The used strains include a deletion mutant of $g r / R A$ (control; indicated as $\mathrm{GrIR}^{-} \mathrm{A}^{-}$); this mutant complemented with plasmids expressing GrIA, GrlA $\Delta$, GrIRA and GIRA $\Delta$, as indicted above the lanes. All strains contained a compatible GFP-expressing plasmid via the ler promoter. (b) Secreted proteins were concentrated from supernatants of bacterial culture grown in DMEM and resolved using $12 \%$ SDS-PAGE. These samples were then transferred to a PVDF membrane and analysed using a monoclonal antibody against representative secretory protein EspB. The strains used are as in $\mathbf{a}$, but all lack the GFP-expressing plasmid. Strains are indicated above the lanes as in $\mathbf{a}$.

a

a $\mathrm{GrlA} \Delta$

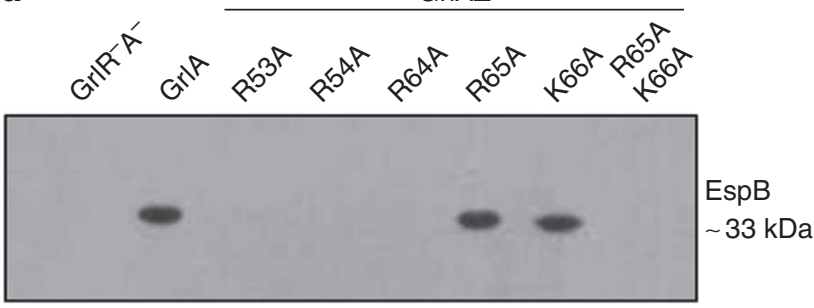

b

$\mathrm{GrlA} \Delta$

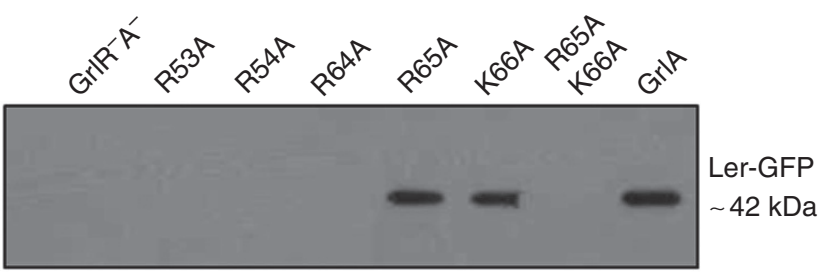

Figure 8 | In vivo analysis of the importance of key HTH motif residues in GrIA-DNA binding. (a) Secreted proteins were concentrated from supernatants of bacterial culture grown in DMEM and resolved in $12 \%$ SDS-PAGE. The samples were then transferred to a PVDF membrane and analysed using polyclonal antiserum against representative secretory protein EspB. The used strains include a deletion mutant of grlRA (control) (indicated as $\mathrm{GrIR}^{-} \mathrm{A}^{-}$); this mutant complemented plasmids expressing GrlA or different GrlA $\Delta$ substitutions, as indicated above the lanes (b). Immunoblot analysis using anti-GFP antibodies to compare the expression of GFP via the ler promoter. The used strains are similar to those described in $\mathbf{a}$, with the exception that all contain a compatible GFP expression plasmid via the ler promoter. Strains are indicated above the lanes.

of GrlR with the C-terminal region of $\mathrm{GrlA}^{8}$. However, we could not confirm this finding in the present complex structure because of the absence of the C-terminal region (aa107-137) of GrlA in the crystallized construct, wherein the majority of GrlA $\Delta$ 
interactions occurs with one monomer of the dimeric GrlR. Despite this, we were able to verify the binding of full-length GrlA to GrlR using ITC and pull-down experiments (Fig. 4a, Supplementary Fig. S5c and Supplementary Table. S1). The ITC experiments indicated that full-length GrlA binds to GrlR with a $\sim 35$-fold higher affinity than GrlA $\Delta$. These results suggest the role of the GrlA C terminus in its interaction with GrlR. Despite this difference in affinity, under the employed experimental conditions, GrlA $\Delta$ exhibited an activity comparable to full-length GrlA (Fig. 7a,b).

Previous studies of the GrlR-GrlA interaction were performed with glutatione S-transferase-tagged proteins ${ }^{8,10}$. These studies suggest that the glutathione S-transferase tag might interfere with the interaction, and could be the reason for the complete disruption of GrlA binding with GrlR following alanine substitution in the ${ }^{46} \mathrm{EDED}^{49}$ motif in our previous study ${ }^{8}$. To avoid this potential pitfall, the current experiments were carried out using MBP-tagged GrlA. We and others have independently verified that $\mathrm{MBP}$ is not involved in the GrlA-GrlR interaction ${ }^{10}$.

Here we show that substitutions in the HTH motif of GrlA $\Delta$ interfered with GrlR binding, whereas the full-length GrlA with substitutions in the $\mathrm{HTH}$ region was able to bind to GrlR probably through its C-terminal region (Figs $4 \mathrm{~b}$ and $5 \mathrm{a}$, Supplementary Fig. S5c; Supplementary Table S1). Jimenez et al. ${ }^{10}$ show that GrlA $\Delta^{1}(\mathrm{aa} 1-100)$ was able to pull down $\mathrm{GrlR}$, and our observation of two binding sites agrees with this finding. Thus, even though the binding site located to the GrlA C terminus was deleted, these deletion constructs can still pull down GrlR via this alternative binding site located at the HTH region.

Our data shows that GrlR interacts with GrlA to prevent its binding to target DNA. The fact that $\operatorname{grl} R$ and $\operatorname{grl} A$ are cotranscribed raises the question that under what conditions GrlA can escape suppression by GrlR and interact with its target DNA. Given the tight GrlR-GrlA mode of interaction and the observation that two GrlR molecules are to needed suppress one GrlA molecule, it can be assumed that GrlA will function as a regulator only when its steady-state level reaches more than half of that for GrlR. The relative steady-state level of the two proteins is controlled by their relative translation rates and stability. Although virtually nothing is known about the first, it is expected that the translation rate would be equal in generating both GrlR bound, as well as free, GrlA. The differential stability and specific GrlR degradation by ClpXP has been previously reported ${ }^{6}$. An additional point of view on this system is that GrlR in complex with GrlA stabilizes GrlA and maintains it in an inactive state that can become functional and rapidly released following an appropriate signal and ClpXP-mediated GrlR degradation.

In conclusion, the present study revealed the molecular structure and mechanism of the GrlR-GrlA complex. GrlR and the promoter regions of $l e r, f h D C$ and $e h x C A B D$ compete for the HTH motif region of GrlA. GrlR outcompetes with these promoter DNA sequences for GrlA. Regulation of multiple virulence operons by a central heterotrimeric GrlR-GrlA complex would help the pathogen to precisely control the expression of various genes involved in its pathogenesis. By differentially regulating the ler and ehx operons positively and the $f h D C$ operon negatively, GrlR and GrlA coordinate and optimize gene expression by the pathogen during the infection process.

\section{Methods}

Plasmid and strain construction. Bacterial strains and plasmids used in this study are listed in Supplementary Table S2. Intact grlR and grlA genes were PCRamplified from EHEC EDL933 (ref. 22) chromosomal DNA and cloned into MCS1 (with a $6 \mathrm{His}$ tag) and MCS2 of the pETDuet-1 (Novagen, Madison, WI, USA) vector, respectively. Plasmid pET32-grlR was constructed by amplifying the $g r l R$ gene from EHEC EDL933 chromosomal DNA and cloning into pET32 vector. Plasmid pGEX-grlA and pMBP-grlA were constructed by amplifying the $g r l A$ DNA fragments from EHEC EDL933 chromosomal DNA and cloning into pGEX-4T1 (GE Healthcare, Buckinghamshire, UK) and pMAL-c2X (New England Biolabs, Ipswich, MA, USA), respectively. The EPEC $g r l R A$-null mutant ( $\triangle g r l R A:: \mathrm{kn})$ was constructed by replacing the grlRA gene from an EPEC strain with a kanamycin cassette by the one-step method using the $\lambda$-recombinase system ${ }^{23}$. Site-specific mutations in $g r l A$ were introduced by overlapping $\mathrm{PCR}^{24}$, which uses complementary oligodeoxyribonucleotide (oligo) primers and the PCR to generate two DNA fragments having overlapping ends. These fragments are annealed, allowing the $3^{\prime}$-overlap of each strand to serve as a primer for the $3^{\prime}$-extension of the complementary strand. The resulting fusion product is amplified further by PCR. Specific mutations in the nucleotide sequence were introduced by incorporating nucleotide changes into the overlapping oligo primers. Each construct was verified by DNA sequencing. To construct pGY1, a DNA fragment containing $\mathrm{P}_{L E E 1}$ and ler (starting from position - 159 compared with the transcriptional start site) was amplified using specific primers; this amplified fragment was digested by XbaI and BamHI and cloned into pIR1 digested by the same enzymes ${ }^{20,25}$. The null strain $(\Delta g r l R A:: \mathrm{kn})$ transformed with pGY1 was named GY2155.

GrIR-GrIA $\Delta$ complex structure determination. pETDuet1-grlR-grlA $\Delta$ plasmid was transformed into E. coli BL21 cells and grown in defined M9 medium ${ }^{26}$ supplemented with $25 \mathrm{mgl}^{-1} \mathrm{~L}$-SeMet at $37^{\circ} \mathrm{C}$ until the optical density reached 0.6 at $600 \mathrm{~nm}$. A 1-litre culture was induced with $100 \mu \mathrm{M}$ isopropyl $\beta$-D-1thiogalactopyranoside and grown overnight at $20^{\circ} \mathrm{C}$. Cells were then collected by centrifugation and resuspended in $40 \mathrm{ml}$ of lysis buffer $(50 \mathrm{mM}$ Tris- $\mathrm{HCl}(\mathrm{pH} 7.0)$, $0.2 \mathrm{M} \mathrm{NaCl}, 1 \%$ (w/v) Triton X-100, 5\% (w/v) glycerol, $10 \mathrm{mM} \beta$-mercaptoethanol) with complete protease inhibitors (Roche Applied Science, Mannheim, Germany). The GrlA-GrlR $\Delta$ complex was purified in two steps using Ni-NTA (Qiagen, Valencia, CA, USA), followed by gel filtration (Superdex75, GE Healthcare). The 6 His tag remained intact on GrlR. Drops containing $1 \mu \mathrm{l}$ of protein solution $\left(7 \mathrm{mg} \mathrm{ml}^{-1}\right)$ and $1 \mu \mathrm{l}$ of reservoir solution were equilibrated by hanging-drop vapour diffusion at $25^{\circ} \mathrm{C}$. The best crystals were grown from $12 \%$ PEG 3350, $0.1 \mathrm{M}$ sodium malonate $\mathrm{pH} 5$ and $0.4 \mathrm{M}$ non-detergent sulphobetaines 201 , with the protein in $30 \mathrm{mM}$ Tris- $\mathrm{HCl}(\mathrm{pH} 7.0), 200 \mathrm{mM} \mathrm{NaCl}$ and $5 \%(\mathrm{w} / \mathrm{v})$ glycerol. One complex consisted of two GrlR and one GrlA $\Delta(2: 1)$ molecule in the asymmetric unit, which accounts for a Matthews coefficient of $2.40 \AA^{3} \mathrm{Da}^{-1}$ (ref. 27), corresponding to a solvent content of $49 \%$. Crystals were cryoprotected in the reservoir solution supplemented with $25 \%$ glycerol and flash cooled at $100 \mathrm{~K}$. The structure was determined using SeMet-labelled protein crystals by singlewavelength anomalous dispersion ${ }^{28}$. X-ray diffraction data were collected at beamline 13B1, National Synchrotron Radiation Research Centre (Taiwan), using a Quantum-315r charge-coupled device area detector (ADSC) and processed with HKL2000 (ref. 29). All of the expected eight Se sites of an asymmetric unit were located using the programme Phenix-Autosol. The phases were further improved by density modification using RESOLVE ${ }^{30}$, which gave a final overall figure of merit of 0.70 . Over $50 \%$ of the backbone atoms of the model were built by RESOLVE. The remaining residues were manually built using COOT $^{31}$ and refined with phenix-refine ${ }^{32}$. Refinement was continued until the $R$-value converged to $0.18\left(R_{\text {free }}=0.23\right)$ for reflections I $>\sigma$ (I) to $2.7 \AA$ resolution (Table 1$)$. The model had good stereochemistry, with $99.3 \%$ residues falling within the allowed regions of the Ramachandran plot. Subsequently, the importance of the key residues in the HTH motif region was validated by structure-based in vitro studies, such as ITC and pull-down assay (see Supplementary Methods).

Analytical ultracentrifugation. The stoichiometric ratio of WT GrlR-GrlA complex was investigated by monitoring their sedimentation properties in sedimentation velocity experiments. Samples $(400 \mu \mathrm{l})$ were used at $A 280 \mathrm{~nm}$ of 1.0 in $30 \mathrm{mM}$ Tris- $\mathrm{HCl}$ (pH 7.0), $200 \mathrm{mM} \mathrm{NaCl}$ and 5\% glycerol. Sedimentation velocity profiles were collected by monitoring the absorbance at $280 \mathrm{~nm}$. The samples were sedimented at 40,000 r.p.m. at $20^{\circ} \mathrm{C}$ in a Beckman Optima XL-I centrifuge (Beckman Coulter Inc., Brea, CA, USA) fitted with a four-hole AN-60 rotor and double-sector aluminium centre pieces, and equipped with absorbance optics. A total of 200 scans were collected and analysed using the Sedfit programme ${ }^{33}$.

Circular dichroism spectrometry. Far ultraviolet spectra (260-190 nm) of MBPGrlA/MBP-GrlA $\Delta$ and its substituents were measured using a Jasco J-810 spectropolarimeter (Jasco Europe, Milan, Italy) in phosphate buffer ( $\mathrm{pH} 7.5$ ) at room temperature using a $0.1-\mathrm{cm}$ path length and stoppered cuvettes. Six scans were recorded, averaged and the baseline subtracted.

Isothermal titration calorimetry. MBP-GrlA, MBP-GrlAA (with or without substitutions in the HTH motif region) and GrlR were all purified in gel filtration buffer containing $30 \mathrm{mM}$ Tris- $\mathrm{HCl}$ ( $\mathrm{pH} 7.0$ ), $200 \mathrm{mM} \mathrm{NaCl}$ and $5 \%$ glycerol. ITC experiments were carried out using a VP-ITC calorimeter (Microcal, LLC, Northampton, MA, USA) at $25^{\circ} \mathrm{C}$ using $0.01 \mathrm{mM}$ protein (MBP-GrlA/MBPGrlA $\Delta$ ) in the sample cell and $0.15-0.22 \mathrm{mM}$ GrlR in the injector. All samples were 
thoroughly degassed and then centrifuged to remove precipitates. Excluding the first $2-\mu l$ injection, $10-\mu l$ injections were sequentially made in each experiment. Consecutive injections were separated by $5 \mathrm{~min}$ to allow the peak to return to baseline levels. ITC data were analysed with a model considering a single class of binding sites implemented in Origin 7.0 (Origin Lab Corp., Northampton, MA, USA) software.

Electrophoretic mobility shift assays. EMSA assays were performed by mixing $\sim 100 \mathrm{ng}$ of DNA (promoter region of ler $(-275 /+217$; numbers indicate the number of base pairs upstream and downstream from the functional ATG start codon, respectively), flhDC $(-455 /+223)$ or $e h x C A B D(-261 /+22)$ with increasing concentrations of purified WT or mutant MBP-GrlA proteins in binding buffer containing $10 \mathrm{mM}$ Tris- $\mathrm{HCl}(\mathrm{pH} 8), 50 \mathrm{mM} \mathrm{KCl}, 1 \mathrm{mM}$ dithiothreitol, $0.5 \mathrm{mM}$ EDTA, $10 \mu \mathrm{g} \mathrm{ml}^{-1} \mathrm{BSA}$ and $5 \%$ glycerol. The primers used to amplify the promoter regions are shown in Supplementary Table S3. Reaction mixtures were incubated for $30 \mathrm{~min}$ at room temperature and then separated by electrophoresis on $5 \%$ polyacrylamide gels in $0.5 \times$ Tris-borate-EDTA buffer. DNA bands were stained with ethidium bromide and visualized with a Syngene transilluminator (Syngene, Frederick, MD, USA). For competitive EMSA assays, DNA was incubated with $1 \mu \mathrm{M}$ MBP-GrlA for $30 \mathrm{~min}$, followed by the addition of increasing concentrations of His-GrlR for an additional $30 \mathrm{~min}$ at room temperature. The complexes were visualized as described above. The formation of GrlR-GrlA complex in the competitive EMSA assay was verified by setting up a $300-\mu \mathrm{l}$ amylose-resin-bound MBP-GrlA-DNA-binding reaction for $30 \mathrm{~min}$. A $30-\mu \mathrm{l}$ sample was run as input on EMSA assay and SDS-PAGE, and the rest was washed several times with excess DNA-binding buffer before titrating with GrlR. A 30- $\mu$ l sample was run after titrating with GrlR followed by washes. The final beads and all other washes along with the initial samples were analysed on both EMSA and SDSPAGE gels. All the EMSA studies were repeated three times and the results were consistent.

Extracellular protein extraction and detection. Overnight cultures of EPEC strains were grown in DMEM medium (Invitrogen, Carlsbad, CA, USA) and supplemented with $30 \mu \mathrm{g} \mathrm{ml}^{-1}$ of kanamycin, $40 \mu \mathrm{g} \mathrm{ml}^{-1}$ streptomycin and $34 \mu \mathrm{g} \mathrm{ml}^{-1}$ chloramphenicol until the optical density at $600 \mathrm{~nm}$ reached 0.8 . The cultures were diluted 1:50 into fresh DMEM medium and incubated for $9 \mathrm{~h}$ at $37^{\circ} \mathrm{C}$ in a shaking water bath at 200 r.p.m. Bacterial cells were centrifuged at $5,500 \mathrm{~g}$ for $10 \mathrm{~min}$ at $4^{\circ} \mathrm{C}$ and the supernatants were passed through a $0.22-\mu \mathrm{m}$ filter (Millex, Millipore). The extracellular protein fraction was isolated by trichloroacetic acid precipitation and the protein pellet was washed thrice with $-20^{\circ} \mathrm{C}$ acetone and then air dried ${ }^{34}$. Extracellular protein pellets were solubilized in Ready Prep reagent $3(5 \mathrm{M}$ urea, $2 \mathrm{M}$ thiourea, $2 \%(\mathrm{w} / \mathrm{v})$ CHAPS, $2 \%(\mathrm{w} / \mathrm{v})$ SB 3-10, $40 \mathrm{mM}$ Tris and $0.2 \%(w / v)$ Bio-Lyte 3/10 ampholyte (Bio-Rad, Hercules, CA, USA)), and stored at $-80^{\circ} \mathrm{C}$, as described ${ }^{34}$. Proteins were transferred to a polyvinylidene difluoride (PVDF) membrane. EspB was detected by the addition of diluted anti-EspB $(1: 2,000)$ polyclonal antiserum, followed by a 1:5,000 dilution of mouse anti-rabbit IgG horseradish peroxidase (1:5,000; Santa Cruz Biotechnology, Santa Cruz, CA, USA). The PVDF membrane was examined using the SuperSignal WestPico Chemiluminescent substrate (Pierce Biotechnology; Rockford, IL, USA) under the conditions recommended by the manufacturer.

ler-gfp Promoter assay. The plasmid pGY1 contains a transcriptional fusion of the $g f p$ to the ler gene and its regulatory region ${ }^{20}$. The plasmid was transformed into the EPEC grlRA::kn mutant strain EM3715 to create strain GY2155. EPEC strain GY2155 was then transformed with a compatible, pACYC184-based plasmid, expressing GrlA or GrlA $\Delta$ and various grlA mutants. The constructed strains were grown in DMEM overnight as described above. Cells were then collected by centrifugation at $5,500 \mathrm{~g}$ for $10 \mathrm{~min}$ at $4{ }^{\circ} \mathrm{C}$ and resuspended in lysis buffer $(1 \times$ PBS) with complete protease inhibitors (Roche Applied Science). The cells were lysed and centrifuged down at $30,000 \mathrm{~g}$ for $30 \mathrm{~min}$. Protein concentrations in the supernatant were adjusted and separated on an SDS-PAGE, transferred to a PVDF membrane and subjected to western blotting. GFP was detected by the addition of diluted anti-GFP $(1: 2,000)$ rabbit monoclonal antibody (Invitrogen), followed by a 1:5,000 dilution of mouse anti-rabbit IgG horseradish peroxidase (Santa Cruz Biotechnology). The PVDF membrane was examined using the SuperSignal WestPico Chemiluminescent substrate under the conditions recommended by the manufacturer.

\section{References}

1. Nataro, J. \& Kaper, J. Diarrheagenic Escherichia coli. Clin. Microbiol. Rev. 11, 142-201 (1998).

2. Pennington, H. Escherichia coli O157. Lancet 376, 1428-1435 (2010).

3. Deng, W. et al. Dissecting virulence: systematic and functional analyses of a pathogenicity island. Proc. Natl Acad. Sci. USA 101, 3597-3602 (2004).

4. Barba, J. et al. A positive regulatory loop controls expression of the locus of enterocyte effacement-encoded regulators Ler and GrlA. J. Bacteriol. 187, 7918-7930 (2005).
5. Bustamante, V. H. et al. PerC and GrlA independently regulate Ler expression in enteropathogenic Escherichia coli. Mol. Microbiol. 82, 398-415 (2011).

6. Iyoda, S. et al. The GrlR-GrlA regulatory system coordinately controls the expression of flagellar and LEE-encoded type III protein secretion systems in enterohemorrhagic Escherichia coli. J. Bacteriol. 188, 5682-5692 (2006).

7. Iyoda, S. \& Watanabe, H. ClpXP protease controls expression of the type III protein secretion system through regulation of RpoS and GrlR levels in enterohemorrhagic Escherichia coli. J. Bacteriol. 187, 4086-4094 (2005).

8. Jobichen, C. et al. Structure of GrlR and the implication of its EDED motif in mediating the regulation of type III secretion system in EHEC. PLoS Pathog. 3, e69 (2007).

9. Jobichen, C. et al. Identification and characterization of the lipid-binding property of GrlR, a locus of enterocyte effacement regulator. Biochem. J. 420, 191-199 (2009).

10. Jiménez, R., Cruz-Migoni, S. B., Huerta-Saquero, A., Bustamante, V. H. \& Puente, J. L. Molecular characterization of GrlA, a specific positive regulator of ler expression in enteropathogenic Escherichia coli. J. Bacteriol. 192, 4627-4642 (2010).

11. Kitagawa, R., Takaya, A. \& Yamamoto, T. Dual regulatory pathways of flagellar gene expression by ClpXP protease in enterohaemorrhagic Escherichia coli. Microbiology 157, 3094-3103 (2011).

12. Fujita, Y. \& Taguchi, H. Overview and outlook of Toll-like receptor ligandantigen conjugate vaccines. Ther. Deliv. 3, 749-760 (2012).

13. Deretic, V. Autophagy as an innate immunity paradigm: expanding the scope and repertoire of pattern recognition receptors. Curr. Opin. Immunol. 24, 21-31 (2012).

14. Schmidt, H., Beutin, L. \& Karch, H. Molecular analysis of the plasmid-encoded hemolysin of Escherichia coli O157:H7 strain EDL 933. Infect. Immun. 63, 1055-1061 (1995).

15. Welch, R. A. \& Pellett, S. Transcriptional organization of the Escherichia coli hemolysin genes. J. Bacteriol. 170, 1622-1630 (1988).

16. Issartel, J. P., Koronakis, V. \& Hughes, C. Activation of Escherichia coli prohaemolysin to the mature toxin by acyl carrier protein-dependent fatty acylation. Nature 351, 759-761 (1991).

17. Wagner, W., Vogel, M. \& Goebel, W. Transport of hemolysin across the outer membrane of Escherichia coli requires two functions. J. Bacteriol. 154, 200-210 (1983).

18. Holm, L. \& Sander, C. Touring protein fold space with Dali/FSSP. Nucleic Acids Res. 26, 316-319 (1998).

19. Mellies, J., Elliott, S., Sperandio, V., Donnenberg, M. \& Kaper, J. The Per regulon of enteropathogenic Escherichia coli: identification of a regulatory cascade and a novel transcriptional activator, the locus of enterocyte effacement (LEE)-encoded regulator (Ler). Mol. Microbiol. 33, 296-306 (1999).

20. Yerushalmi, G., Nadler, C., Berdichevski, T. \& Rosenshine, I. Mutational analysis of the locus of enterocyte effacement-encoded regulator (Ler) of enteropathogenic Escherichia coli. J. Bacteriol. 190, 7808-7818 (2008).

21. Saitoh, T. et al. Transcription of the ehx enterohemolysin gene is positively regulated by GrlA, a global regulator encoded within the locus of enterocyte effacement in enterohemorrhagic Escherichia coli. J. Bacteriol. 190, 4822-4830 (2008).

22. Hayward, R. D., Leong, J. M., Koronakis, V. \& Campellone, K. G. Exploiting pathogenic Escherichia coli to model transmembrane receptor signalling. Nat. Rev. Microbiol. 4, 358-370 (2006).

23. Datsenko, K. A. \& Wanner, B. L. One-step inactivation of chromosomal genes in Escherichia coli K-12 using PCR products. Proc. Natl Acad. Sci. USA 97, 6640-6645 (2000).

24. Ho, S. N., Hunt, H. D., Horton, R. M., Pullen, J. K. \& Pease, L. R. Site-directed mutagenesis by overlap extension using the polymerase chain reaction. Gene 77, 51-59 (1989).

25. Friedberg, D., Umanski, T., Fang, Y. \& Rosenshine, I. Hierarchy in the expression of the locus of enterocyte effacement genes of enteropathogenic Escherichia coli. Mol. Microbiol. 34, 941-952 (1999).

26. Doublié, S. Preparation of selenomethionyl proteins for phase determination. Methods Enzymol. 276, 523-530 (1997).

27. Matthews, B. Solvent content of protein crystals. J. Mol. Biol. 33, 491-497 (1968).

28. Terwilliger, T. \& Berendzen, J. Bayesian correlated MAD phasing. Acta Crystallogr. D Biol. Crystallogr. 53, 571-579 (1997).

29. Otwinowski, Z. \& Minor, W. Processing of X-ray diffraction data collected in oscillation mode. In Methods in Enzymology. Vol. 276, 307-326 (Academic Press (1997).

30. Terwilliger, T. SOLVE and RESOLVE: automated structure solution and density modification. Methods Enzymol. 374, 22-37 (2003).

31. Emsley, P. \& Cowtan, K. Coot: model-building tools for molecular graphics. Acta Crystallogr. D Biol. Crystallogr. 60, 2126-2132 (2004). 
32. Adams, P. D. et al. PHENIX: a comprehensive Python-based system for macromolecular structure solution. Acta Crystallogr. D Biol. Crystallogr. 66, 213-221 (2010).

33. Schuck, P. Size-distribution analysis of macromolecules by sedimentation velocity ultracentrifugation and lamm equation modeling. Biophys. J. 78, 1606-1619 (2000).

34. Li, M. et al. Comparative proteomic analysis of extracellular proteins of enterohemorrhagic and enteropathogenic Escherichia coli strains and their ihf and ler mutants. Appl. Environ. Microbiol. 70, 5274-5282 (2004).

35. Delano, W. L. The PyMOL molecular graphics system. http://pymol.sourceforge.net (2002).

\section{Acknowledgements}

This work was partially supported by a BMRC grant (WBS R154000461305) from the Agency for Science Technology and Research (A*STAR), Singapore. We acknowledge the National Synchrotron Radiation Research Centre beamline 13B1 of the Taiwan synchrotron facility. I.R. was supported by a grant from the Israeli Science Foundation (ISF). K.Y.L. was supported by a grant from the Natural Science and Engineering Research Council (NSERC) Discovery Grant (372373-2010), Canada and Open Funding Project of the State Key Laboratory of Bioreactor Engineering of China. We acknowledge the assistance provided by Dr Gal Yerushalmi in plasmid construction. A.P. is a graduate scholar in receipt of a research scholarship from the National University of Singapore (NUS)

\section{Author contributions}

J.S. conceived and designed the study. A.P. performed cloning, expression, purification crystallization, data collection and biophysical analysis. C.J. and A.P. performed the crystallographic calculations and analysis. E.M. generated the null mutants and ler-gfp plasmids. A.V.-C. analysed the ITC data. K.Y.L., Y.K.M. and L.M. were involved in the analysis. A.P., C.J., I.R. and J.S. wrote the paper.

\section{Additional information}

Accession code: Coordinates of GrlR:GrlA $\Delta$ complex have been deposited in the Protein Data Bank under accession code 4KT5.

Supplementary Information accompanies this paper at http://www.nature.com/ naturecommunications

Competing financial interests: The authors declare no competing financial interests.

Reprints and permission information is available online at http://npg.nature.com/ reprintsandpermissions/

How to cite this article: Padavannil, A. et al. Structure of GrlR-GrlA complex that prevents GrlA activation of virulence genes. Nat. Commun. 4:2546 doi: 10.1038/ ncomms3546 (2013) 